\title{
Sexual Periodicity and the Causes which Determine It*
}

\author{
By Dr. F. H. A. Marshall, C.B.E., F.R.S.
}

SEXUAL periodicity, like all vital phenomena, $S$ is conditioned by the environment. Under the term 'environment' are included food, light, temperature, the humidity of the atmosphere and in aquatic species of animals, the hydrogen ion concentration of the medium and all the other chemical and physical conditions of the surroundings.

In all animals with reproductive organs, there is a tendency to an alternation of periods of activity and periods of rest associated with the development of the gonads and their exhaustion after they have discharged their products, as seen especially in those animals which spawn in bulk. In the lower animals in which there is no nervous system, the environment must be supposed to act directly upon the organism, and so influence the rhythm of reproduction. But in the higher animals sexual periodicity is determined and regulated by special factors which, though generally similar, show great variation in passing from group to group and from species to species and even from breed to breed.

These factors are : (1) endocrine factors associated especially with the gonads (and their successive functional phases) and with the anterior pituitary ; and (2) exteroceptive factors which through the intermediation of the nervous system act upon and modify the endocrine factors. In the male mammal the testes produce a hormone, testosterone, which is responsible for all the changes which take place in the accessory sexual organs and in the secondary male characters in association with the sexual season; the testis is acted upon by a hormone formed by the anterior pituitary, and the latter organ is influenced by exteroceptive and possibly also other stimuli coming from the outside environment. In the majority of animals, light is probably the most important factor, but there are others.

In this way, the sexual rhythm is normally brought into relation with the seasonal changes, and the activity of the anterior pituitary and that of the testes rise and fall almost simultaneously. The accessory organs may be brought into a state of activity outside the normal breeding season by the injection of testicular hormone, by the injection of an anterior pituitary hormone, and, in many species also, by light irradiation.

In the female mammal, the processes are similar but the matter is complicated by the occurrence of pregnancy and, in polyœstrous species, by the

* Substance of the Croonian Lecture delivered before the Royal Society on June 18. recurrence of heat periods at short intervals within the sexual season. There are two main phases of ovarian activity: (1) the follicular or œstrous phase which is induced by the ovarian hormone, cestradiol ; and (2) the luteal phase of pregnancy, pseudo-pregnancy and the short diœstrous interval (in polyœestrous species), which are generally controlled by the hormone progesterone formed by the corpus luteum. The œestrous-producing substances found in the urine and elsewhere during pregnancy and the ostrin in the urine of the male are to be regarded as metabolic products of no physiological significance in relation to the control of the cycle, and it is to be pointed out, first, that many other substances having œestrogenic properties when injected into animals experimentally, have been extracted from organisms both animal and vegetable or even have been prepared synthetically, and secondly, that the œstrins which are excreted during pregnancy occur in the urine mostly in a combined and inactive form.

The endocrine activities of the ovaries are themselves controlled by the anterior pituitary, but whether there is one or more than one gonadstimulating hormone formed by the anterior pituitary is still doubtful. It appears certain, however, that the secretory activity of the anterior pituitary must vary quantitatively if not qualitatively in different phases of the œestrous cycle. In species like the rabbit and the ferret which normally only ovulate after the orgasm, the switch over from the oestrous to the luteal phase of the cycle is effected by the anterior pituitary, and can be induced experimentally by the injection of a pituitary extract or by electrical stimulation of the central nervous system, thereby producing a general stimulus comparable to the orgasm. Moreover, in the rat, which ovulates spontaneously, a comparable condition of pseudo-pregnancy can be induced by experimental stimulation. The duration of the corpus luteum therefore may depend upon a hormonic stimulus from the anterior pituitary.

Further, the condition of pregnancy apparently reacts upon the pituitary and so controls the duration of the corpus luteum of pregnancy, and in rats stimulation of the nipple by sucking or artificially by other means and without the secretion of milk, will react on the pituitary and maintain the corpus luteum of lactation. In the absence of any exteroceptive stimuli which alter the phases of the cycle, the alternation between the oestrous phase and the diœstrous phase may 
be controlled by the ovary and anterior pituitary acting and reacting on one another, the pituitary initiating the œstrogenic activity of the ovary, which then has a temporary inhibiting effect on the stimulating capacity of the pituitary until such time as the production of œstrin is reduced, when the pituitary responds by an increased production of ovary-stimulating hormone. There is certain experimental evidence for this view.

The phase of lactation, also, is believed to be con. trolled by the anterior pituitary, and a substance has been extracted from it which stimulates milk secretion. The same substance, which is called prolactin, will also stimulate the crop gland in the pigeon and induce incubation. This is in conformity with the view that the reproductive hormones were metabolic by-products before they acquired hormonic activities, and that other organs and tissues in the body gradually learnt, so to speak, to respond to their presence in the progress of evolution and so promote functional correlation between different parts of the body.

In the female mammal, like the male, light and ultra-violet irradiation may induce oestrus outside the breeding season, the stimulus probably acting upon the pituitary. The same is true for many species of birds, but both in mammals and birds there is much species variation, each kind of animal requiring its own appropriate stimulus of light or other factors. The successive phases of the cycle in birds are likewise under the influence of anterior pituitary gonad-stimulating mechanisms, but they are very liable to be interfered with by exteroceptive stimuli.

In most birds ovulation depends upon coition, or at any rate on sexual display, and there is evidence that courtship phenomena play an important part in effecting the necessary synchronisation of the anterior pituitary processes in the male and female. Such a theory as to the biological value of sexual display and adornment may take the place of the Darwinian theory of sexual selection, and without encountering the difficulties in the way of that theory, one of the most formidable of which is the fact that birds of many species pair before they display and often pair for life. The biological disadvantages of an ineffective synchronisation between the various generative functions is illustrated from the domestic animals, in which temporary sterility is common.

\section{The Universities of Great Britain: Education for a Living and for Life}

\section{$\mathrm{T}$} HE universities of Great Britain have shown remarkable buoyancy in the rough weather produced by the world-wide financial and economic stresses of 1930 and following years. So much is clear from the University Grants Committee's recently published report* for the period 1929-30 to 1934-35. A perusal of the Committee's previous reports makes it equally clear that this steadiness in the face of adversity is attributable in no small measure to the Committee's own foresight, watchfulness, sympathetic understanding and wise counsel. Appointed by the Chancellor of the Exchequer in 1919 to advise the Govermment as to the needs of university education in Great Britain, this Standing Committee has used with such tact and good sense its unrivalled opportunities of insight into university affairs as to enable it to play, with acceptance, the far more exacting and delicate role of adviser to the universities. "There has been," to quote the words

* University Grants Committee. Report for the period 1929-30 to 1934-35, including Returns from Universities and University Colleges in receipt of Treasury Grant for Academic Year 1934-35. (London : H.M. Stationery Office, 1936.) 48. net. The Report is signed by Sir Walter H. Moberly (chairman), Sir Arthur W. Hill, Sir Geo. Macdonald, Sir Humphry Rolleston, Prof. G. I. Taylor, Prof. W. P. Wynne, Miss Margery Fry, Sir Frederic G. Kenyon, Sir Stanley Leathes (the
membership of the last three dating back to the first appointment of membership of the last three dating back to the first appo
the Committee in 1919) and John Beresford, secretary. of Dr. Ernest Barker in The Times of April 18, "fostering care without control; there has been guidance and suggestion without command. The British universities draw one third of their annual revenue from the Parliamentary grants distributed by the Committee; but it is safe to say that not one of them has felt a feather-weight of domination from the Committee."

The past six years saw notable increases in university student enrolments, and great improvements in accommodation for laboratories, libraries, medical schools, research institutes, halls of residence and students' unions. A statistical table elsewhere in this article shows an increase in student numbers of eleven per cent as compared with an increase in the preceding quinquennium of three per cent; but the rate of increase is now slackening. Accumulated deficits were brought down from $£ 200,000$ to $£ 72,000$; capital benefactions were at the rate of a million pounds a year; additions to general endowment funds amounted to $£ 2,280,000$; but endowment incomes dropped owing to reduction in interest rates.

After reviewing salient developments since 1929, the Committee proceeds to a consideration of 